\title{
Ecological Risk Assessment Approach of Offshore Macro-engineering Project Based on US Environmental Protection Agency Framework
}

\author{
Zijian Guo, Yuexin Zhang, Yun Peng, and Wenyuan Wang
}

\begin{abstract}
Offshore macro-engineering project plays an important role in promoting regional economic development. Macro-engineering projects are marked by high investment, long duration, adverse environmental condition, and high difficulty in estimating impacts in ecology. As an important component of environment risk assessment in the stage of feasible study before construction, ecology risk assessment is required in accordance with Chinese laws. However, critical assessing frameworks have not been established yet in China. Additionally, the shortage of characteristic data is another dilemma in marine ecosystem research. Therefore, in this paper, the US Environmental Protection Agency (USEPA) framework is adopted for ecological risk assessment and statistical method is used to estimate the data distribution according to the finite sample. Finally, a case study of Bohai Strait Channel project is analyzed with USEPA framework.
\end{abstract}

Index Terms-Marco-engineering project, USEPA framework, ecological risk assessment, offshore engineering.

\section{INTRODUCTION}

Ecological risk assessment (ERA) before construction of projects is required by most governments around the world. Macro-engineering projects (MEPs) can bring significant affection to ecology environment; therefore, ERA of such projects is particularly important. According to Peng et al., when investment exceeds one billion US dollars, the projects can be called MEPs [1]. The ERA of MEPs is complex. Fortunately, it is generally accepted that ERA need to be carried out under systematic framework to provide valuable reference information for risk managers to develop their decisions.

Up till now, many countries have established their own ecological risk assessment frameworks.

In the guidelines proposed by the US Environmental Protection Agency (USEPA) in 1988, USEPA framework is established in purpose of standardizing procedure in ecological risk assessments [2]. In the framework, the roles of risk assessors, risk managers and interested parties are clarified. A consistent procedure which contains 5 aspects as planning, ecological risk assessment, data collecting and analyzing, communication with risk manager and risk management is introduced. Also, the risk assessment process

Manuscript received May 9, 2017; revised August 2, 2017. This work was supported in part by the National Natural Science Foundation of China (No. 51279026 and No. 51309049 ).

The authors are with the Dalian University of Technology, Dalian, 116024 China (e-mail: zjguo@dlut.edu.cn, cindych1217@mail.dlut.edu.cn, yun_peng@dlut.edu.cn,wangwenyuan@dlut.edu.cn). is mainly divided into 3 phases: problem formulation, analysis, and risk characterization.

The framework of US has been modified for soil contamination in Australia [3]. The ecological risk assessment phase consists of two steps: primary ERA and definitive ERA. The primary ERA is conducted in most situations in the scope of protecting the site. If low risk is obtained, no further assessment is needed. On contrast, if the site is under risk, further studies should be conducted for definitive ERA which is considered to take more effort and time. Toxicity assessment is required in the frame work for soil pollution and ecological investigation levels (EILs) are introduced.

UK established an ERA framework consists of 3 tiers [4]. After the desk study of risk, Tier 1 is to evaluate the significance of risk with soil screening values (SSV). When Tier 2 is the detailed risk assessment, and ecological survey or bioassays can be used for quantitatively describing the risk. In Tier 3, the data and relations and harm to the receptors are considered to obtain the cause-effect attribution. The Australian framework and the UK framework mainly focus on soil contamination, and the value limits provided are not suitable for evaluating offshore projects.

Although specific risk assessment framework is limited, the investigation on ecological risk assessment is conducted by researchers all over the world.

Various materials are used to study the extent of pollution and to evaluate the condition of ecological environment. Sediment is examined with toxicity methods to evaluate the environmental risks by the level of contamination of the sediment [5]. A framework has been established for traits-based assessment to evaluate the vulnerability of traits in 3 aspects: external exposure, intrinsic sensitivity and population sustainability [6]. Various of risk assessments have been conducted on different kinds of stressors that may cause a impact to the ecology. $\mathrm{Li}$ and You conducted an assessment based on the toxicity of the main contamination of cypermethrin on the ecology of a river [7]. To assess the ecological risk of contamination to coastal water in China under USEPA framework, Gao et al. studies the concentration of nonylphenol [8] and Luo et al. studies the sediments polluted with arsenic and metals [9]. Duration and accumulation of stressors are also focused by previous researchers. Cumulative effects assessment of watershed conditions is conducted in Canada from 2008 to 2013 for future prediction and planning [10]. Short term [11] to long term [12] investigations on pollution have also been conducted for ERA. USEPA framework is adopted by Liu to 
conduct ecological risk assessment of ports [13].

Most of the frameworks and studies mentioned above mainly focus on other fields or risk assessment of one single stressor. For offshore MEPs, there is no specific ERA method in the overall perspective by far. Among the frameworks mentioned, the USEPA framework is a general framework, and has been effective since 1998 and adopted by a lot of ERA frameworks which makes it possible to adopt it for offshore MEPs. In this paper, USEPA framework is introduced in conducting ERA of offshore MEPs. In this process, statistical method of finite sample data analyzing is utilized in data processing section.

This paper is divided into 4 sections. Section II introduces the ERA methodology presented in the USEPA framework and the assessing methodology based on finite sample points. In Section III, a case study of risk assessment of Bohai Strait Channel project is presented. In Section IV, conclusions are drawn and suggestions are made for further studies.

\section{MethodOLOGY}

\section{A. USEPA Framework}

USEPA framework proposed a well-organized procedure for ecological risk assessment. In the framework, three participants are mentioned, risk assessors, risk managers and interested parties, among which risk assessors and risk managers are the major participants to accomplish risk assessment. Risk managers contribute more in discussion, and decision making, while risk assessors are responsible for the providing required scientific analysis results. The methodology mentioned in this paper focuses on the mission of risk assessors.

The standard procedure of USEPA framework consists of 5 phases: planning, ecological risk assessment, data collecting and analyzing, communication with risk manager and risk management. The framework is shown in Fig. 1.

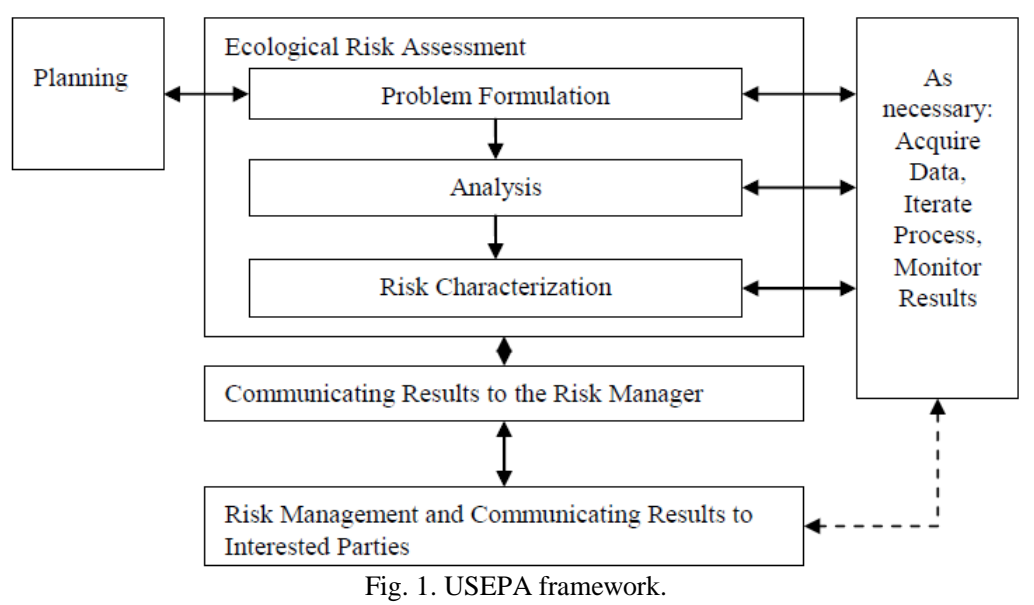

1) Planning. During the planning phase, risk managers and risk assessors should work together to discuss the validity of a risk assessment. When the following goals are reached, it can be regarded as the end of the planning phase: ecological value management objectives, management options, objectives such as criteria for success, key points and extension, the availability of resource.

2) Ecological risk assessment. Ecological risk assessment is the most important phase for obtaining all the supporting information for risk managers to make managing decisions. It is divided into 3 steps: problem formulation, analysis, and risk characterization. Assessors can follow the proposed steps to accomplish ecological risk assessment. It should be aware that during the process of each step, data acquiring and processing should be combined when necessary to achieve effective results. During problem formation phase, the risk assessors aim to propose three primary products: assessment goals, characterization of decisions, agreement on the scope and focus of the assessment with desired production. The analysis phase is processed to examine the risk exposure and ecological effects, and the interaction between the two together with ecosystem characteristics. This phase aims to obtain exposure and ecological effect profiles for further derivation of risk characterization. Characterization of exposure studies the measures of exposure ecosystem and receptor characteristics to draw the exposure profile through exposure analysis. Ecological effects characterization reaches the stressor-response profile with measures of effect and ecosystem and measures of receptor characteristics by ecological response analysis.

3) Data collecting and analyzing. Data collecting and analyzing should be processed for scientific evidence when necessary. In this study, statistical methods are used in the process.

4) Communication with risk manager. Risk assessors should communicate with risk managers after risk analysis and decide whether the result is sufficient for risk management.

5) Risk management. When the risk analysis and characterization is completed, risk managers can make management decisions based on the assessment results.

As quantitation of risk is not always possible, this study aims to describe the stressor-response relationship of the ecology in macro-engineering projects and analyze the existing data to estimate the impact of the project on the ecological environment.

\section{B. Assessment Based on Finite Sample Points}

Since the survey of ecology of the ocean is costly, and some stressor-response relationship is complex to clarify, existing finite sample data has been studied and statistical methods are used to estimate the range of target parameters when data 
processing is necessary. The process is shown in Fig. 2.

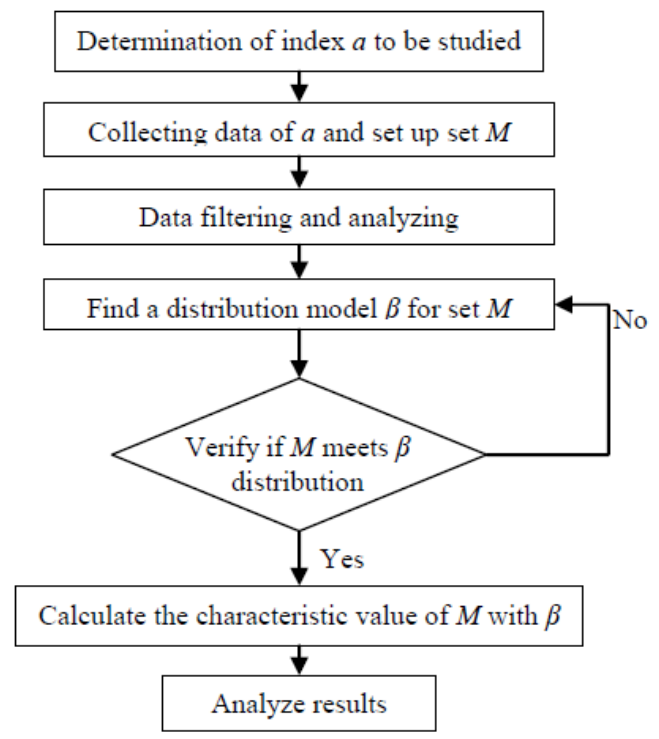

Fig. 2. Process of finite sample data analyzing.

1) First, the target index $a$ is determined from problem formulation, risk analysis phase. Then, empirical data from similar projects which are lying in the same sea area should be collected. The sample size can be determined from the following equation:

$$
n=Z^{2} S^{2} / D^{2}
$$

where $n$ is the required sample size, $Z$ is the statistics of $Z$ at a certain confidence level, $S$ is the overall standard deviation, $d$ is the permissible error. It is a single objective investigation for every environment effective index, and it is required that for significance tests, sample capacity should be no less than 30. Sample capacity over 100 is preferred, if possible.

2) Second, the collected data should be processed. Significant errors should be eliminated. Data should be normalized by area and arrayed in ascending order for further analysis. Then, the characteristics of the sample should be analyzed and a proper general distribution model which satisfies $\gamma$ test should be built to describe the distribution of the sample [14].

Assuming that $\Omega_{1}$ is the rejection domain for the problem $H_{0}: \theta \in \phi_{0} \leftrightarrow H_{1}: \theta \in \phi_{1}$, and the test function is formulated as follows:

$$
g(\theta)=P\left\lfloor\left(X_{1}, X_{2} \ldots \ldots, X_{n}\right) \in \Omega \mid \theta\right\rfloor, \theta \in \phi
$$

then,

$$
g(\theta)=\left\{\begin{array}{l}
\gamma(\theta), \theta \in \phi_{0} \\
1-E(\theta), \theta \in \phi_{1}
\end{array}\right.
$$

If $\sup _{\theta \in \phi_{0}} g(\theta) \leq \gamma$, the significant level of $\gamma$ test is satisfied.

3) After the distribution model passes the $\gamma$ test, the expectation value and confidence interval should be set to estimate the range of target parameter.

4) Last, the results from sample should be compared with environment evaluation index to obtain the range of target parameters.

\section{CASE STUDY}

\section{A. Background of Bohai Strait Channel Project}

\section{1) Geographical natural environment}

Bohai is one of China's four seas, with north-south span of 560 kilometers and east-west span of 300 kilometers. The total sea area is 77 thousand square kilometers. The sea is surrounded by lands on three sides, adjacent to Liaoning Province, Hebei Province, Shandong Province and Tianjin Municipality. The open sea side is adjacent to Huanghai with Bohai Strait in between. The distance between the two endpoints, the southern cape of the Liaodong Peninsula Laotieshan Cape and Dengzhou on Shandong Peninsula is 57 miles. The average depth of seabed is $25 \mathrm{~m}$, the maximum depth of $86 \mathrm{~m}$ locates in Laotieshan channel.

Bohai Strait is the necessary to enter Bohai water area, meanwhile, it is also the natural obstacle to block land transportation between Liaoning Province and Shandong Province. There are two traditional options for passengers who travel between Liaoning and Shandong: 8 hours travel by ship or detour almost 1400 kilometers on land when the linear distance is only about 140 kilometers. Fig. 3 shows the traditional route from Dalian to Dengzhou, which is shown in purple.

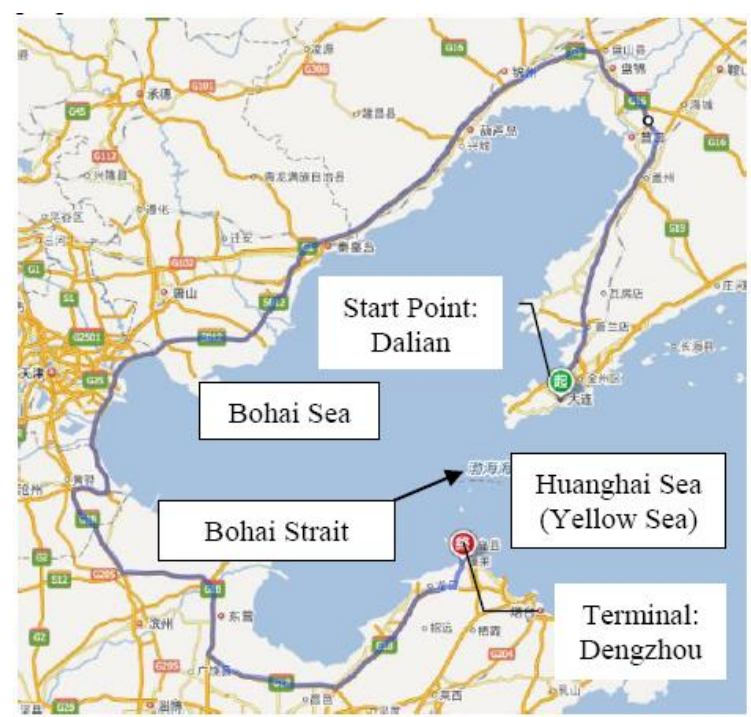

Fig. 3. Traditional routes from Dalian to Dengzhou.

\section{2) "Tunnel on the north and Bridges on the south" scheme}

Since the concept of transportation channel across Bohai Strait was proposed, many plans were raised. Among the plans, "Tunnel on the north and Bridges on the south" scheme is considered to be the most feasible and economical solution. The scheme suggested that tunnel should be built on the north section of the strait (Laotieshan Cape-North Huangcheng Island) not only because of the large width, depth and complex topography and hydrological conditions of the waterway but the navigation requirements should also be considered as the north section of the channel is the main access to Bohai sea. Considering the undulating topography of seabed, an improved immersed tunnel which is a combination of immersed tunnel anchored on the seabed and tunnel bridges under water is designed for the north section of 
the channel. In the south section of the channel, the terrain rises and a series of islands array along the route, which provide perfect natural foundations for bridges.

\section{3) Ecological environment background}

In this section, the ecological environment of Bohai Sea area is introduced. General investigations have been conducted on plankton, intertidal benthos, benthos, necton, vegetation, terrestrial animals and birds.

\section{a) Plankton condition}

The species and amount of phytoplankton and zooplankton vary from seasons. The information of phytoplankton and zooplankton are listed in Table I and Table II.

TABLE I: PHytopLANKTON IN DALIAN SEA AREA

\begin{tabular}{cccccc}
\hline \hline Seasons & Units & Spring & Summer & Autumn & Winter \\
\hline Average number & $10^{3}$ cells $/ \mathrm{m}^{3}$ & 2595.4 & 303.8 & 480.55 & 2202.4 \\
Maximum & $10^{3}$ cells $/ \mathrm{m}^{3}$ & 16854.5 & 1324 & 1925 & 7580 \\
Minimum & $10^{3}$ cells $/ \mathrm{m}^{3}$ & 65 & 48 & 48 & 480 \\
& & Melosira sulcata, & Chaetoceros, & Melosira sulcata, & Melosira sulcata, \\
& & C.jonesianus, & Melosira, & C.jonesianus, & C.jonesianus, S. \\
Main Species & & Rhixosolenia & Leptosianus, & Leptocylindrus \\
& & Stytiformis & danicus & costatum & \\
\hline \hline
\end{tabular}

TABLE II: ZOOPLANKTON IN DALIAN SEA AREA

\begin{tabular}{cccccc}
\hline \hline Seasons & Units & Spring & Summer & Autumn & Winter \\
\hline Average number & $\mathrm{mg} / \mathrm{m}^{3}$ & 34.42 & 111 & 59.9 & 59.1 \\
Maximum number & $\mathrm{mg} / \mathrm{m}^{3}$ & 59 & 173 & 130 & 96 \\
Minimum number & $\mathrm{mg} / \mathrm{m}^{3}$ & 15 & 33 & 23 & 21 \\
\hline \hline
\end{tabular}

b) Intertidal benthos condition

The number of intertidal benthos varies from spring to autumn. In spring, The total average biomass is $806 \mathrm{~g} / \mathrm{m}^{2}$, the average density is $129 / \mathrm{m}^{2}$. The dominant species is mussel which takes up $30 \%$ of the total biomass and $54.3 \%$ in counting. The second dominant species in spring is ulva lactuca, takes up $23.2 \%$ of total biomass. On contrast, the total average biomass in autumn is $72 \mathrm{~g} / \mathrm{m}^{2}$, the average density is $15 / \mathrm{m}^{2}$, both are about $1 / 10-1 / 8$ of the value in spring. The dominant species are Mactra veneriformis and ruditapes philippinarum. The proportions of total biomass are $52 \%$ and $33 \%$ respectively.

\section{c) Benthos condition}

Benthic community is composed of various species such as Echinodermata, Mollusca, Crustacea, and Coelenterate. Rays and Mantis Shrimp take up $32.75 \%$ and $24.16 \%$ of necton biomass respectively in spring, while baby croaker and small ribbon fish account for $34.11 \%$ and $13.99 \%$ in autumn. Konosirus punctatus and rays are dominant species in summer and winter, respectively.

\section{d) Vegetation condition}

Due to the impact of marine climate, natural condition of this area is superior, the vegetation belongs to the warm temperate zone of the northern summer green broad-leaved forest and deciduous Quercus liaotungensis sub zone, so there are unique species that distribute in limited areas, such as Acacia, Broussonetia papyrifera, Evodia daniellii and Harlequin glorybower etc.. There are species imported from the south, such as fir, cedar, three ball Platanaceae, eucommia, Indus etc. Vegetation in this area is relatively good, plenty of forest vegetation, especially pine forest accounted for a large proportion.

\section{e) Terrestrial animals condition}

There are two national nature reserves near the project site: Dalian Harbor Seal National Reserve and Shedao Nature Reserve. The sites are shown in Fig. 4. The reserved species are harbor seals and gloydius shedaoensis which is a unique species of viper that can be found no where else.

\section{f) Birds condition}

Laotieshan (Fig. 4), due to its special geographical location, has become one of the important stops for millions of migratory birds in Northeast Asia. Spring migration peak from South Australia to Siberia is generally in March May; the return migration peak is usually in the middle of late October. Laotieshan is well known as the "relay station" for migratory birds because the birds gather here to rest and replenish energy for coming long distance travel across the strait.

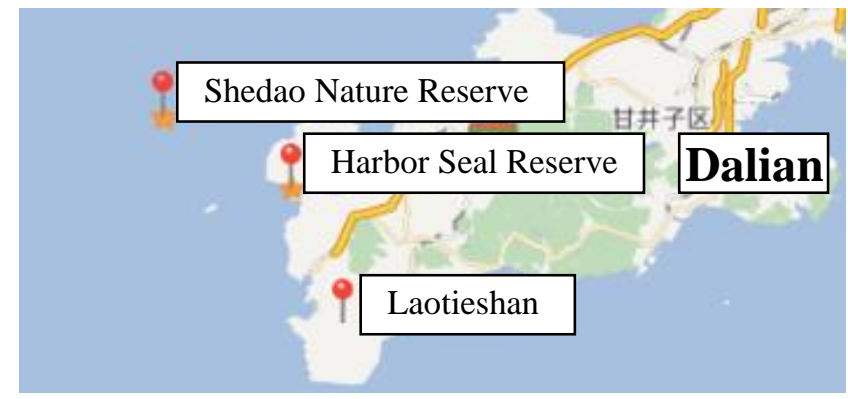

Fig. 4. Map of nature reserves

As recorded, there are over 300 species of birds have been witnessed, accounting for $20 \%$ of national bird species and $50 \%$ of northeast bird species. Among which 9 species are Class 1 under national protection, and 45 species belongs to Class 2. 167 species are found in the protection list of 227 species of birds listed China-Japan Migratory Bird Agreement, the percentage is $70.9 \%$.

\section{B. Ecological Risk Assessment of Bohai Straits Cross-Sea} Channel Based on USEPA Framework

In this section an ERA based on USEPA framework is conducted to investigate the effectiveness of the framework.

\section{1) Problem Formulation}

The key points of this phase are to identify the assessment 
endpoints and establish conceptual models to make a plan for the following phase of risk analysis.

In this study, the risk caused by the tunnel construction and operation is mainly discussed. The construction and operation will bring great change in under water ecological environment Therefore the assessment endpoints are decided to be survival of plankton, intertidal benthos, benthos and necton.

Conceptual model is hypothesis that describes the stress-response relationship during exposure. To obtain conceptual models, ecological risk exposure path is first illustrated in Fig. 5.

As the port ecological stressor is shown in Fig. 5. Exposure conceptual model and response conceptual model are constructed to describe the interaction between the sea area of risk source, stressor, and receptor endpoints. The conceptual model is shown in Table III and Table IV response. In Table III, the stressors subjected to the receptors are described in abbreviations, where H- Hydrology, W-Water quality, LLand resource, A- Air quality, N-noise.

In Table IV, the abbreviations stand for different ways of exposure for assessment endpoints. F-Feeding, N-Nesting,

\section{B-Breeding.}

\section{2) Risk analysis}

In this study, data from 173 coastal projects in the Bohai sea area has been collected and proceeded. The distribution of data was found to match with log-normal distribution with finite sample points assessment method. Then, K-S test has been conducted to examine the logarithmic normal distribution significance of data samples [15]. The sample data distribution and theoretical distribution was considered no significant differences when the significance value exceeds 0.05 . All of the significance values exceed 0.05 , the average significance value is 0.479 which indicate that the theoretical distribution can be applied to describe the data distribution. The upper and lower limit of confidence interval of 0.8 is accepted. The results are shown in Table V and Table VI.

\section{3) Characterization of ecological effects}

Similar data process was conducted to estimate the biomass loss of benthos and necton. The average significance value is 0.586 .



Fig. 5. Ecological risk exposure approaches of Bohai Strait Channel project.

TABLE III: EXPOSURE CONCEPTUAL MODEL FOR BOHAI STRAIT ECOLOGICAL RISK

\begin{tabular}{ccccccc}
\hline \hline Receptor & $\begin{array}{c}\text { Engineering } \\
\text { Structures }\end{array}$ & $\begin{array}{c}\text { Construction } \\
\text { Waste }\end{array}$ & Sewerage & Dust & $\begin{array}{c}\text { Veihical and } \\
\text { Machinery }\end{array}$ & $\begin{array}{c}\text { Accidents } \\
\text { Products }\end{array}$ \\
\hline Ocean & L & W L & W & & & W \\
Intertidal Zone & H L & W L & W & A & A & W A \\
Islands & L & L & & A & A N & A \\
\hline \hline
\end{tabular}

TABLE IV: RESPONSE CONCEPTUAL MODEL FOR BOHAI STRAIT ECOLOGICAL RISK

\begin{tabular}{cccccccc}
\hline \hline Receptor & Plankton & Benthos & Necton & Intertidal Benthos & Vegetation & Terrestrial Animals & Birds \\
\hline Ocean & F N B & F N B & F N B & F & & & \\
$\begin{array}{c}\text { Intertidal } \\
\text { Zne }\end{array}$ & & & F & F N B & & F & F \\
Islands & & & & & F N B & F N B & F N B \\
\hline \hline
\end{tabular}

TABLE V: ANALYSIS OF DATA OF STRESSORS

\begin{tabular}{|c|c|c|c|c|c|c|c|}
\hline Stressor & Categories & $\begin{array}{c}\text { Index } \\
\text { Examined }\end{array}$ & Units & $\begin{array}{l}\text { Significance } \\
\text { from K-S Test }\end{array}$ & $\begin{array}{l}\text { Lognormal } \\
\text { Expectation }\end{array}$ & $\begin{array}{c}\text { 0.8 Confidence } \\
\text { Interval Upper Limit }\end{array}$ & $\begin{array}{c}0.8 \text { Confidence Interval } \\
\text { Lower Limit }\end{array}$ \\
\hline Hydrology & Water velocity & Variation & $\mathrm{m} / \mathrm{s}$ & 0.462 & 0.034 & 0.423 & 0.003 \\
\hline \multirow{4}{*}{$\begin{array}{l}\text { Water } \\
\text { quality }\end{array}$} & & Rate & & 0.533 & $16.2 \%$ & $31.7 \%$ & $8.2 \%$ \\
\hline & Waste water & Emission & $\mathrm{m}^{3} /\left(\mathrm{d} \cdot \mathrm{hm}^{2}\right)$ & 0.932 & 1.126 & 22.052 & 0.057 \\
\hline & Solid waste & Emission & $\mathrm{kg} /\left(\mathrm{d} \cdot \mathrm{hm}^{2}\right)$ & 0.195 & 7.741 & 104.730 & 0.005 \\
\hline & Suspended-particle & Intensity & $\mathrm{kg} /\left(\mathrm{s} \cdot \mathrm{hm}^{2}\right)$ & 0.271 & 0.050 & 0.539 & 0.072 \\
\hline
\end{tabular}


TABLE VI: ANALYSIS OF DATA OF ENDPOINTS

\begin{tabular}{ccccccc}
\hline \hline Endpoints & $\begin{array}{c}\text { Index } \\
\text { Examined }\end{array}$ & Units & $\begin{array}{c}\text { Significance from K-S } \\
\text { Test }\end{array}$ & $\begin{array}{c}\text { Lognormal } \\
\text { Expectation }\end{array}$ & $\begin{array}{c}0.8 \text { Confidence Interval } \\
\text { Upper Limit }\end{array}$ & $\begin{array}{c}0.8 \text { Confidence Interval } \\
\text { Lower Limit }\end{array}$ \\
\hline \multirow{2}{*}{ Benthos } & $\begin{array}{c}\text { Biomass } \\
\text { loss }\end{array}$ & $\mathrm{t} / \mathrm{hm}^{2}$ & 0.129 & 0.900 & 11.183 & 0.072 \\
& $\begin{array}{c}\text { Fish egg } \\
\text { loss } \\
\text { Necton } \\
\text { Offspring } \\
\text { loss }\end{array}$ & $10^{4} / \mathrm{hm}^{2}$ & 0.855 & 0.772 & 20.000 & 0.030 \\
\hline \hline
\end{tabular}

\section{CONCLUSIONS}

In conclusion, this paper discussed the ecological risk assessment of offshore MEPs in 4 aspects. First, the USEPA framework is introduced as guidance for the assessment. The methods suggested in the framework are effective and instructive for ERA work. It offers an efficient aid in analyzing, categorizing and choosing stressors, receptors, endpoints and interaction paths at different levels which is a key obstacle in risk assessments. Second, a large range of stressors are considered in exposure characterization. Conceptual model is established and analyzed based on the investigation of sample project which offers a suggestion for ERA of offshore MEPs. Third, data processing method based on finite samples is conducted, and log-normal distribution is found to be in reasonable agreement with data distribution, the feasibility is examined by K-S test. Average significance values of 0.479 and 0.586 indicate that the log-normal distribution describes the data distribution well. Also, the confidence interval of 0.8 also indicates the accuracy. The significance of this is to introduce data processing suggestion into offshore MEPs ERA framework, which can obtain not only qualitative analysis but also quantitative results. Last, the risk of biomass loss of two kinds of receptors is predicted.

The major contributions of this paper are introducing the USEPA framework for the ecological risk assessment of offshore macro-engineering projects; proposing the risk exposure conceptual model of Bohai Strait Channel project based on the USEPA framework and obtaining quantitative assessment results based on finite ecological data samples.

For further study, more exposures should be considered such as the natural accidents and interaction among species. More data of previous projects in different sea area should also be studied for experience in ecological protection and affection. New method of data processing can be introduced for more accurate and targeted prediction.

\section{REFERENCES}

[1] Q. Peng, Z. Wu, and N. Li, "Early stage characteristics of Macro engineering and suggestions for the taiwan strait tunnel project," Marine Georesources \& Geotechnology, vol. 21, pp. 279-288, July 2003.

[2] Guidelines for Ecological Risk Assessment, USA, EPA/630/R-95/002F (1998).

[3] National Environment Protection (Assessment of Site Contamination) Measure 1999 Schedule b5a Guideline on Ecological Risk Assessment. Australia F2013C00288 (1999).

[4] Ecological Risk Assessment Framework for Contaminants in Soil, Rio House SC070009/SRI (2008).

[5] R. B. Choueri, A. Cesar, D. M. S. Abessa et al., "Harmonised framework for ecological risk assessment of sediments from ports and estuarine zones of North and South Atlantic," vol. 19, pp. 678-696, April 2010.

[6] M. N. Rubach, R. Ashauer et al., "Framework for traits-based assessment in ecotoxicology," Integrated Environmental Assessment and Management, vol. 7, issue 2, pp. 172-186, April 2011.
[7] H. Z. Li and J. You, "Application of species sensitivity distribution in aquatic probabilistic ecological risk assessment of cypermethrin: A case study in an urban stream in South China," Environmental Toxicology and Chemistry, vol. 34, no. 3, pp. 640-648, March 2015.

[8] P. Gao, Z. Y. Li, M. Gibson, and H. W. Gao, "Ecological risk assessment of nonylphenol in coastal waters of China based on species sensitivity distribution model," Chemosphere, vol. 104, pp. 113-119, June 2014

[9] W. Luo, Y. L. Lu, T. Y. Wang et al., "Ecological risk assessment of arsenic and metals in sediments of coastal areas of nothern Bohai and Yellow Seas, China," AMBIO, vol. 39, issue 5, pp. 367-375, July 2010.

[10] M. G. Dubé, P. Duinker, L. Grelg et al., "A framework for assessing cumulative effects in watersheds: An introduction to Canadian canse studies," Integrated Environmental Assessment and Management, vol. 9, issue 3, pp. 363-369, July 2013.

[11] R. A. Hoke, L. D. Bouchelle, B. D. Ferrell, and R. C. Buck, "Comparative acute freshwater hazard assessment and preliminary PNEC development for eight fluorinated acids," Chemosphere, vol. 87, issue 7, pp. 725-733, Jan. 2012.

[12] J. A. Dellinger, M. D. Moths, M. J. Dellinger, and M. P. Ripley, "Contaminant trends in freshwater fish from the Laurentian Great Lakes: A 20-year analysis," Human and Ecological Risk Assesment, vol. 20, issue 2, pp. 461-476, March 2014.

[13] G. L. Liu, "Port ecological risk comprehensive assessment method based on USEPA framework," MS thesis, Department of Port, Coastal and Offshore Engineering, Dalian University of Technology. Dalian, China; 2014.

[14] L. L. Wei, J. H. Ma, and R. F. Yan, An Introduction to Probability and Statistics, Beijing: Science Press; 2012.

[15] A. W. Azim, S. S. Khalid, and S. Abrar, "Modulation classification based on modified Kolmogorov-Smirnov test," Emerging Technologies(ICET), pp. 1-6, vol. 9, 2013.

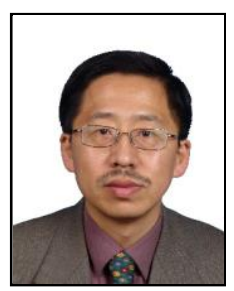

Zijian Guo was born in Shenyang, China, on May12, 1965. He received the B.E. degree in port and waterway engineering from Dalian University of Technology, Dalian, China in 1987. He received his M.Sc. degree and Ph.D. degree from Nihon University, Japan in 1992 and 1995 respectively.

$\mathrm{He}$ is a professor and doctoral advisor in the Faculty of Infrastructure Engineering, Dalian University of Technology (No. 2 Linggong Road, Ganjingzi District, Dalian City, Liaoning Province, China). From 1999 to 2001, he was a post-doctoral fellow of the Department of Civil Engineering, University of Tokyo, Japan. Later, he worked as a post-doctoral fellow in UPS Center for Worldwide Supply Chain Management, University of Louisville, USA in 2002. He is editor-in-chief of Port Planning and Layout (third edition) (Beijing: China Communications Press, 2011). His research interest covers Optimization of the Integrated Transport System and Port System \& Logistics.

Prof. Guo is the vice dean of Institute of international shipping center, and director of office of Port Development Research Centre Dalian University of Technology. He awarded third prize on China Navigation Science and Technology Award and third prize on Liaoning Province Natural Science Academic Achievement Award.

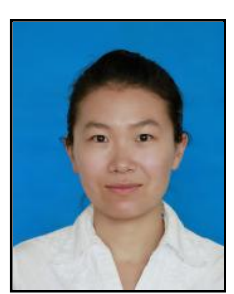

Yuexin Zhang was born in Shenyang, China, on December 17, 1984. She received the B.E. degree in port, waterway and coastal engineering from Dalian University of Technology, Dalian, China, in 2007, and the MPhil degree in civil and environmental engineering from the Hong Kong Polytechnic University, Hong Kong, China, in 2013. She is now a $\mathrm{PhD}$ candidate major in engineering management in Dalian University of Technology.

She is a PhD candidate in Dalian University of Technology (No. 2 
Linggong Road, Ganjingzi District, Dalian City, Liaoning Province, China) and a lecturer in Liaoning Provincial College of Communications. She used to work in Maritime Bureau of Liaoning Province from 2007 to 2009 as a clerk. Her research interests include structural engineering, civil and environmental risk assessment.

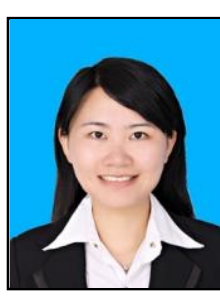

Yun Peng was born in Tieling, China, on November 16, 1988. She received her bachelor degree in port, waterway and coastal engineering from Tianjin University in 2010, and doctoral degree in port, coastal and offshore engineering from Dalian University of Technology.

She is a lecturer of Infrastructure Engineering at Dalian University of Technology (China). From 2013 to 2015 , she was a visiting student at University of California, Davis, USA. Her recent published articles are: A stochastic seaport network retrofit management problem considering shipping routing design. Ocean \& Coastal Management, 2016; 119:169-176. Optimal allocation of resources for yard crane network management to minimize carbon dioxide emissions. Journal of Cleaner Production, 2016; 131:649-658. Her research interests focus on the layout and planning of green port, and port logistics system simulation and optimization.

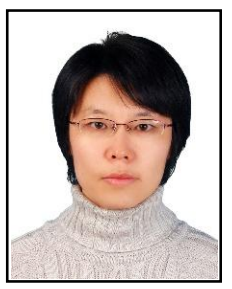

Wenyuan Wang got her bachelor degree in port, waterway and coastal engineering, and master and doctoral degree in harbour, coastal and offshore engineering from Dalian University of Technology.

She is an associate professor of Infrastructure Engineering at Dalian University of Technology (China). Her recent published articles are: "A numerical study of the effects of the T-shaped baffles on liquid sloshing in horizontal elliptical tanks," Ocean Engineering, 2016; "Liquid sloshing in partly-filled laterally-excited cylindrical tanks equipped with multi baffles," Applied Ocean Research, 2016; "Impact of navigational safety level on seaport fairway capacity," Journal of Navigation, 2015. Her research interests are mainly concerned with port layout and planning, multimodal transportation system design. 